\title{
Diagnosis of Streptococcus suis Meningoencephalitis with metagenomic next-generation sequencing of the cerebrospinal fluid: a case report with literature review
}

\author{
Xiaobo Zhang ${ }^{1 *}$, Zhaoping $\mathrm{Wu}^{2}$ and Kai Wang ${ }^{1}$
}

\begin{abstract}
Background: Streptococcus suis meningoencephalitis is a zoonotic disease that mostly infects slaughterhouse workers. Rapid diagnosis of Streptococcus suis meningoencephalitis is critical for effective clinical management of this condition. However, the current diagnostic techniques are not effective for early diagnosis of this condition. To the best of our knowledge, the use of cerebrospinal fluid metagenomic next generation sequencing in the diagnosis of Streptococcus suis meningoencephalitis has been rarely reported.

Case presentation: Here, we report a case of Streptococcus suis meningoencephalitis in a 51-year-old female patient. The patient had a history of long-term contact with pork and had a three-centimeter-long wound on her left leg prior to disease onset. Conventional tests, including blood culture, gram staining and cerebrospinal fluid culture, did not reveal bacterial infection. However, Streptococcus suis was detected in cerebrospinal fluid using metagenomic next generation sequencing.

Conclusions: Metagenomic next generation sequencing is a promising approach for early diagnosis of central nervous system infections. This case report indicates that cases of clinical meningeal encephalitis of unknown cause can be diagnosed through this method.
\end{abstract}

Keywords: Streptococcus suis, Meningoencephalitis, Cerebrospinal fluid, Metagenomic next-generation sequencing

\section{Background}

Streptococcus suis (S. suis) is a zoonotic pathogen that may cause serious illness in pigs and people who have occupational contact with pigs and pork, such as farmers, slaughterhouse workers and butchers [1]. In humans, S. suis infection may cause serious infections and complications including meningitis and septicemia.

\footnotetext{
* Correspondence: 285058041@qq.com

'Department of Neurology, The First People's Hospital Of Changde City, 818 Renmin Road, Changde 415000, Hunan Province, China

Full list of author information is available at the end of the article
}

Meningitis is the most frequent clinical manifestation of S. suis infection, and deafness is the most common sequelae in survivors $[2,3]$. About $50-60 \%$ of S. suis infections occur even in the absence of obvious wounds after contact with pigs or pork, and may be asymptomatic in the early stages. Moreover, disease progression is rapid, and the pathogen may directly enter circulation causing meningeal encephalitis $[2,4]$. However, the clinical incidence of $S$. suis meningitis is very low (3\%) which often leads to misdiagnosis of this condition, especially in the context of pneumococcal meningitis (20\%) and Listeria

(c) The Author(s). 2020 Open Access This article is licensed under a Creative Commons Attribution 4.0 International License, which permits use, sharing, adaptation, distribution and reproduction in any medium or format, as long as you give appropriate credit to the original author(s) and the source, provide a link to the Creative Commons licence, and indicate if changes were made. The images or other third party material in this article are included in the article's Creative Commons licence, unless indicated otherwise in a credit line to the material. If material is not included in the article's Creative Commons licence and your intended use is not permitted by statutory regulation or exceeds the permitted use, you will need to obtain permission directly from the copyright holder. To view a copy of this licence, visit http://creativecommons.org/licenses/by/4.0/ The Creative Commons Public Domain Dedication waiver (http://creativecommons.org/publicdomain/zero/1.0/) applies to the data made available in this article, unless otherwise stated in a credit line to the data. 
monocytogenes meningitis $(36 \%)[5,6]$. Thus, there is a need to develop accurate methods for rapid detection of S. suis to promote effective treatment. Routine microbiological tests are often insensitive against neuroinvasive pathogens. Metagenomic next generation sequencing (mNGS) is a promising, universal pathogen detection method which provides "unbiased" pathogen detection. It can, therefore, be used for the clinical diagnosis of various pathogens, including rare ones $[7,8]$. It is a more accurate method since it relies on DNA sequence information contained in cerebrospinal fluid samples of patients with meningitis or encephalitis [7, 9].

Here, we report a case of $S$. suis meningoencephalitis which was diagnosed with mNGS analysis of cerebrospinal fluid samples. To the best of our knowledge, there are few reports on the application of mNGS to detect pathogens in cerebrospinal fluid (CSF) of patients with S. suis meningoencephalitis. The study was approved by the ethics committee of the First People's Hospital of Changde city and publication of the clinical data was approved by the patient's family.

\section{Case presentation}

Here, we report a case of a 51-year-old female diagnosed with S. suis meningoencephalitis.

The patient was a slaughterhouse worker and had no chronic illnesses. In addition, the patient had no history of alcohol or illicit drug use, but had a three-centimeterlong wound on her left leg before disease onset. The patient presented to our emergency department with a 3day fever, with a temperature of nearly $39.0^{\circ} \mathrm{C}$.

At the time, the patient did not experience any other symptoms, such as cough, expectoration, or chills. Initially, the patient was treated for putative infection at a local clinic (specific treatment information was not available), but her symptoms did not improve significantly. On the 3rd day of symptom onset, she experienced an occipital headache of unknown nature and duration, accompanied by dizziness, nausea and vomiting, without obvious limb weakness, incoherent speech, abnormal mental behavior, convulsion or other discomfort. The patient was transferred to our hospital's emergency department for further treatment. Routine blood analysis at the emergency department revealed a WBC count of $10.56 \times 10^{\wedge}$ 9/L, N\%: $94.4 \%$. A head CT scan did not reveal any obvious abnormality. Within $24 \mathrm{~h}$, the patient was admitted into the intensive care unit. In the morning after admission, a lumbar puncture was performed which showed turbid CSF. The CSF pressure was 310 $(\mathrm{mmH} 2 \mathrm{O})$ and the color of the CSF was light yellow, with slight turbidity. The WBC count was $850 / \mu$ Land the WBCs were multinucleated. Biochemical analysis of the CSF revealed that the levels of glucose, chloride and protein were $0.15 \mathrm{mmol} / \mathrm{L}, 117.5 \mathrm{mmol} / \mathrm{L}$, and $4275 \mathrm{mg} /$
L, respectively. About $5 \mathrm{~mL}$ of the CSF was sent to KingMed Diagnostics for CSF pathogen identification using next generation sequencing. At this time, the patient was treated with meropenem. A repeat lumbar puncture 5 days after symptom onset revealed relatively clear CSF and lower CSF pressure relative to the previous value. CSF WBC count also dropped to $680 / \mu \mathrm{L}$. Biochemical studies demonstrated that the levels of glucose, chloride, and protein were $4.18 \mathrm{mmol} / \mathrm{L}, 124.9 \mathrm{mmol} / \mathrm{L}$, and $1324 \mathrm{mg} / \mathrm{L}$, respectively. Cranial MRI revealed a wide range of enhancement patterns. Viral and tuberculosis tests were negative.

Four days after admission, analysis for wide-spectrum bacterial nucleic acids did not detect bacteria in the CSF. By contrast, CSF mNGS analysis confirmed the presence of $S$. suis with a very large number of sequences (Fig. 1). Very low levels of Streptococcus dysgalactiae were also detected, which was more likely to be non-specific matching of homologous sequences. Studies have shown that Streptococcus dysgalactiae can colonize the skin of humans hence may cause CSF contamination [10]. Together with medical history, we concluded that the patient was infected by $\mathrm{S}$. suis. The patient's EEG showed diffuse slow waves, with no epileptic wave. Repeated lumbar puncture 9 days after admission revealed a CSF pressure of $<180 \mathrm{mmH} 2 \mathrm{O}, \mathrm{WBC}$ count of $40 / \mathrm{ul}$, a glucose level of $3.23 \mathrm{mmol} / \mathrm{L}$, a chloride determination level of $123.2 \mathrm{mmol} / \mathrm{L}$, and a protein level of $703.0 \mathrm{mg} / \mathrm{L}$, indicating marked patient improvement. The results of 4 CSF tests are shown in Table 1.

On the 10th day after admission, the patient was transferred to the general ward and treated with ceftazidime in the subsequent days. Since then, she complained of dizziness and hearing loss. We have attempted to try to correct the hearing loss of the patient by some drugs such as hormones and vitamins, but the effect was not obvious. Repeat lumbar puncture 20 days after symptom onset revealed completely normal values for routine and biochemical CSF analyses. The patient's physical condition also gradually improved and asked to be discharged from hospital. The patient still had some hearing loss at the time of discharge.

During hospitalization, bacterial culture and gram staining of CSF showed normal results. Repeated CSF acid-fast staining was also negative. This indicates that mNGS is more effective than conventional microbial detection methods. Due to its high costs, mNGS reanalysis was not done. At one-month follow-up, the patient still complained of left hearing loss but could function independently.

\section{Discussion and conclusions}

Although intracranial infections are common, the pathogens are not identified in 50\% of intracranial infection 

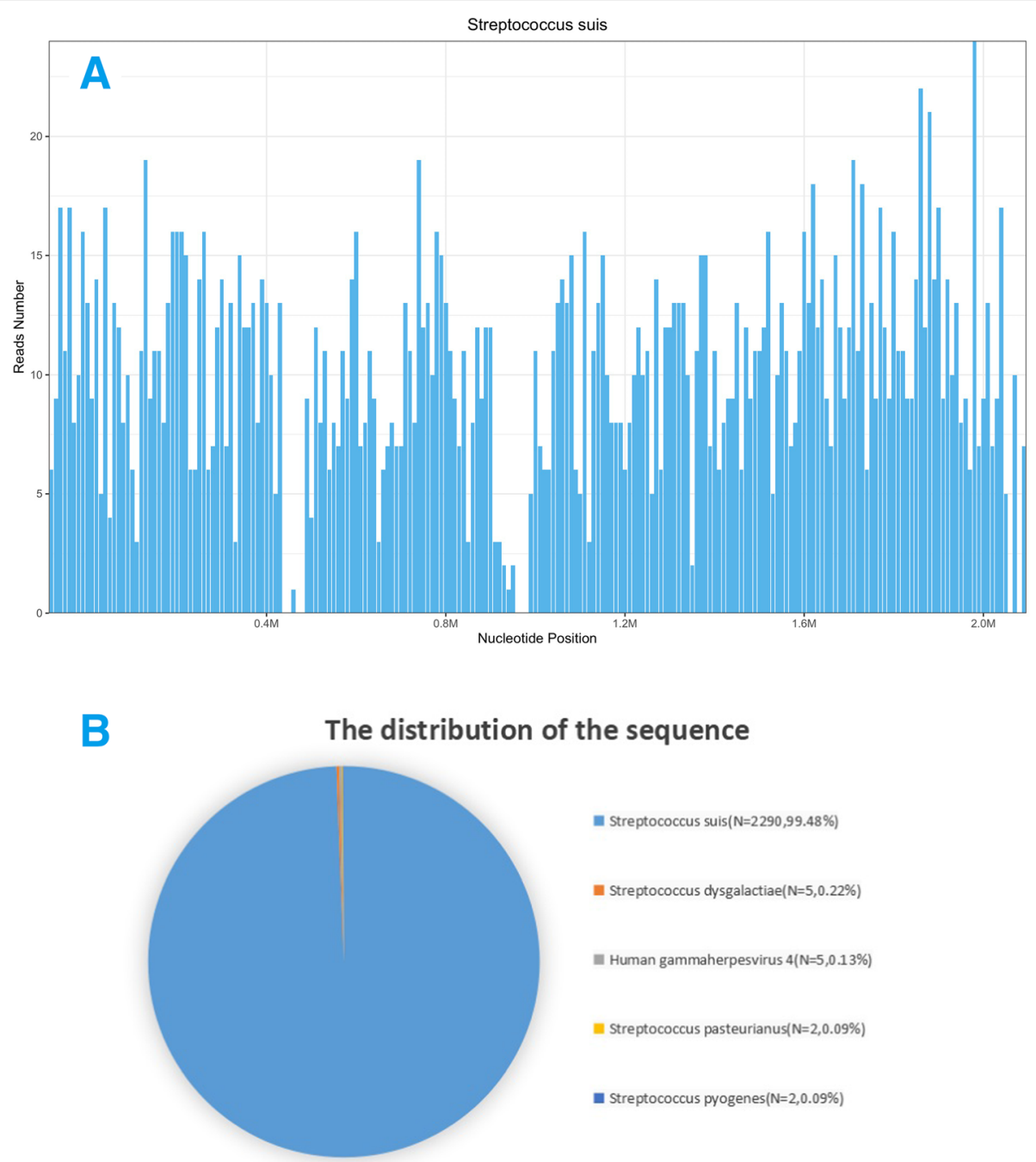

Fig. 1 The majority of reads mapped to the S. suis genome, with coverage of 5.5508\% (a). A total of 2290 sequence reads corresponded to S. suis, accounting for $99.48 \%$ of microbial reads (b)

cases [11]. The bacteria most commonly associated with central nervous system infection and serious intracranial infection include, Neisseria meningitidis and Streptococcus pneumoniae [12]. Streptococcus suis (S. suis) has been reported as a novel emerging zoonotic pathogen. The main risk factors for S. suis infection include occupations related to pigs, exposure to pigs or pork products, and being male [2, 3]. This pathogen is naturally present in piglets and can cause serious human illnesses, including meningitis, endocarditis and septicemia $[2,4]$.
It has been reported that most cases of S. suis meningitis are male. Typical clinical manifestations include hearing loss, fever, headache, and stiff neck, but hearing loss is the most frequent $[2,13]$.

The female patient in this case report presented with fever and headache as first symptoms, which were accompanied with dizziness and unconsciousness. The patient complained of hearing loss during hospitalization. Repeat CSF smear tests, common cultures and CSF broad-spectrum bacterial nucleic acid tests were negative

Table 1 The results of 4 times cerebrospinal fluid of the patient after admission in our hospital

\begin{tabular}{llllll}
\hline Date & Pressure $(\mathbf{m m H} \mathbf{2 O})$ & White blood cell (count/ul) & Protein $\mathbf{( m g / L )}$ & Glucose $(\mathbf{m m o l} / \mathbf{L})$ & Chloride $(\mathbf{m m o l} / \mathbf{L})$ \\
\hline Day 3 of symptom onset & 310 & 850 & 4275 & 0.15 & 117.5 \\
Day 5 of symptom onset & 280 & 650 & 1324 & 2.68 & 124.9 \\
Day 12 of symptom onset & 70 & 40 & 703 & 3.23 & 123.4 \\
Day 20 of symptom onset & 90 & 3 & 325 & 3.68 & 125.7 \\
\hline
\end{tabular}


during hospitalization. For quick, accurate diagnosis, mNGS analysis of CSF was performed which indentified S. suis.

To detect pathogenic microorganisms by mNGS, parallel sequencing of all nucleic acids (DNA and/or RNA) from samples is performed [14, 15]. Although standard microbiological diagnostic techniques fail to detect pathogens in most cases [16-18], unbiased mNGS application successfully identifies causative pathogens in such cases, making mNGS a superior diagnostic tool $[14,18]$. Toshimasa Hayashi successfully identified two clinical isolates of Streptococcus suis (S. suis) in blood samples obtained from two male farmers in Japan using next generation sequencing (NGS), and further confirmed that the two isolates belonged to serotype 2 ST28 [13]. It was also reported that a male patient working as a butcher who injured his finger while handling pork developed sepsis. However, no pathogenic bacteria were found in common blood culture examination. S. suis was confirmed by macrogene second-generation sequencing using blood samples [19]. A critical review of literature revealed that few studies have reported the application of mNGS-based detection to determine the presence of the pathogens in patient blood samples.

To the best of our knowledge, the use of cerebrospinal fluid metagenomic next generation sequencing for the diagnosis of Streptococcus suis meningoencephalitis has been rarely reported. A case of Streptococcus suis meningoencephalitis was diagnosed by next generation sequencing of cerebrospinal fluid metagenome in our department. Initially, mNGS was used to diagnose central nervous system infections, such as chronic infections, and it has since been used to successfully diagnose rare encephalitis, new encephalitis, and atypical infections $[8,16,20]$. For cases of encephalitis with unknown cause, or atypical symptoms, mNGS may be more effective than conventional methods like CSF smear and culture $[8,14,15]$.

Currently, penicillin, ampicillin and 3rd or 4th generation cephalosporin are the most effective agents against S. suis [21]. The patient in this case report had high fever and consciousness disturbance at the time of admission. Cytological and biochemical CSF analyses lead us to conclude that this was a case of severe bacterial meningeal encephalitis. At admission, the patient was treated with meropenem, a strong broad-spectrum antibiotic that penetrates the blood-brain barrier. Five days after admission, second-generation sequencing of the patient's CSF sample confirmed S. suis meningoencephalitis. About 1 week after admission, the patient's symptoms and CSF laboratory test results had improved significantly. Thus, we changed treatment to ceftazidime until routine and biochemical CSF test results were normal.
This study indicates that mNGS analysis of CSF is an "unbiased" pathogen detection method for accurate clinical diagnosis of patients suspected of nervous system infection, even in cases of rare pathogen infection $[8,9]$. Because mNGS can simultaneously examine nucleic acid sequences of a variety of pathogenic microorganisms, including common and rare bacteria, it provides high detection rates, facilitating early initiation of treatment. This improves patient prognosis and minimizes use of non-targeted antibiotics.

\section{Abbreviations}

CSF: Cerebrospinal fluid; NGS: Next-generation sequencing;

mNGS: Metagenomic next-generation sequencing; S.suis: Streptococcus suis

\section{Acknowledgements}

The authors are very grateful to the patient for participating in this study.

\section{Authors' contributions}

XBZ reviewed the literature, analyzed the patient data and wrote the manuscript. KW and ZPW were responsible for data collection. All the authors read and approved the final manuscript.

\section{Funding}

Not applicable.

\section{Availability of data and materials}

The data that support the findings of the current study are available from the corresponding author upon reasonable request.

\section{Ethics approval and consent to participate}

Ethical approval for this study was granted by the ethics committee of the First People's Hospital of Changde city.

\section{Consent for publication}

Written informed consent was obtained from the patient for publication of this case report. A copy of written consent is available for review by the Editor of this journal editor.

\section{Competing interests}

The authors declare that they have no competing interests.

\section{Author details}

${ }^{1}$ Department of Neurology, The First People's Hospital Of Changde City, 818 Renmin Road, Changde 415000, Hunan Province, China. 'Department of Neurology, Second Xiangya Hospital, Central South University, Changsha 410011, Hunan Province, China.

Received: 25 April 2020 Accepted: 15 November 2020

Published online: 25 November 2020

\section{References}

1. Dutkiewicz J, Zając V, Sroka J, Wasiński B, Cisak E, Sawczyn A, et al. Streptococcus suis: a re-emerging pathogen associated with occupational exposure to pigs or pork products. Part II Pathogenesis Ann Agric Environ Med. 2018;25(1):186-203.

2. van Samkar A, Brouwer MC, Schultsz C, van der Ende A, van de Beek D. Streptococcus suis Meningitis: A Systematic Review and Meta-analysis. PLOS Neglected Tropical Dis. 2015;9(10):e0004191.

3. Rayanakorn A, Goh B-H, Lee L-H, Khan TM, Saokaew S. Risk Factors for Streptococcus Suis Infection: A Systematic Review and Meta-Analysis. Sci Rep. 2018;8(1):13358.

4. Feng $Y$, Zhang $H$, Wu Z, Wang S, Cao M, Dan H. Streptococcus suis infection: an emerging/reemerging challenge of bacterial infectious diseases? Virulence. 2014;5(4):477-97.

5. Brouwer MC, Heckenberg SGB, de Gans J, Spanjaard L, Reitsma JB, van de Beek D. Nationwide implementation of adjunctive dexamethasone therapy for pneumococcal meningitis. Neurology. 2010;75(17):1533-9. 
6. Koopmans MM, Brouwer MC, Bijlsma MW, Bovenkerk S, Keijzers W, van der Ende A. Listeria monocytogenes sequence type 6 and increased rate of unfavorable outcome in meningitis: epidemiologic cohort study. Clin Infect Dis. 2013;57(2):247-53.

7. Gu W, Miller S, Chiu CY. Clinical metagenomic next-generation sequencing for pathogen detection. Annu Rev Pathol. 2019;14:319-38.

8. Wilson MR. Actionable diagnosis of neuroleptospirosis by next- generation sequencing. N Engl J Med. 2014;370(25):2408-17.

9. Wilson MR, Sample HA, Zorn KC, Arevalo S, Yu G, Neuhaus J, et al. Clinical Metagenomic Sequencing for Diagnosis of Meningitis and Encephalitis. N Engl J Med. 2019;380(24):2327-40.

10. TakahashiT UK, Watanabe H. Invasive infection caused by Streptococcus dysgalactiae subsp. equisimilis: characteristics of strains and clinical features. J Infect Chemother. 2011;17(1):1-10.

11. Vora M, Holman RC, Mehal JM, Steiner CA, Blanton J, Sejvar J. Burden of encephalitis-associated hospitalizations in the United States 1998-2010. Neurology. 2014;82(5):443-51.

12. Brouwer MC, van DBD. Management of bacterial central nervous system infections. Handb Clin Neurol. 2017;140:349-64.

13. Hayashi T, Tsukagoshi H, Sekizuka T, et al. Next-generation DNA sequencing analysis of two Streptococcus suis ST28 isolates associated with human infective endocarditis and meningitis in Gunma, Japan: a case report. Infect Dis (Lond). 2019:51(1):62-6.

14. Simnera PJ, Millerb S, Carrolla KC. Understanding the promises and hurdles of metagenomic next-generation sequencing as a diagnostic tool for infectious diseases. Clin Infect Dis. 2018;66(5):778-88

15. Brown JR, Bharucha T, Breuer J. Encephalitis Diagnosis Using Metagenomics: Application of Next Generation Sequencing for Undiagnosed Cases. J Inf Secur. 2018;76(3):225-40.

16. Wilson MR, Suan D, Duggins A, Schubert RD, Khan LM, Sample HA, et al. A Novel Cause of Chronic Viral Meningoencephalitis: Cache Valley Virus. Ann Neurol. 2017;82(1):105-14.

17. Pendleton RKM, Erb-Downward JR, Bao Y, Branton WR, Falkowski NR, Newton DW, et al. Rapid Pathogen Identification in Bacterial Pneumonia Using Real-time Metagenomics. Am J Respir Crit Care Med. 2017;196(12): 1610-2.

18. Naccache SN, Peggs KS, Mattes FM, Phadke R, Garson JA, Grant P, et al. Diagnosis of neuroinvasive astrovirus infection in an immunocompromised adult with encephalitis by unbiased next-generation sequencing. Clin Infect Dis. 2015;60(6):919-23.

19. Dai Y, Chen L, Chang W, Lu H, Cui P, Ma X. Culture-Negative Streptococcus suis Infection Diagnosed by Metagenomic Next-Generation Sequencing. Front Public Health. 2019;7:379 Published 2019 Dec 17.

20. Hoffmann B, Tappe D, Höper D, Herden C, Boldt A, Mawrin C, et al. A variegated squirrel Bornavirus associated with fatal human encephalitis. N Engl J Med. 2015;373(2):154-62.

21. Hlebowicz M, Jakubowski P, Smiatacz T. Streptococcus suis meningitis: epidemiology, clinical presentation and treatment. Vector Borne Zoonotic Dis. 2019;19(8):557-62.

\section{Publisher's Note}

Springer Nature remains neutral with regard to jurisdictional claims in published maps and institutional affiliations.

Ready to submit your research? Choose BMC and benefit from:

- fast, convenient online submission

- thorough peer review by experienced researchers in your field

- rapid publication on acceptance

- support for research data, including large and complex data types

- gold Open Access which fosters wider collaboration and increased citations

- maximum visibility for your research: over $100 \mathrm{M}$ website views per year

At BMC, research is always in progress.

Learn more biomedcentral.com/submissions 